\title{
The Effects of Beta-Hydroxy-Beta-Methylbutyrate (HMB) on Body Composition in Trained MMA Fighters
}

Direct Original Research

Jose Rojas ${ }^{1}$, Tobin Silver ${ }^{1}$, Jose Antonio ${ }^{1}$, Corey A. Peacock ${ }^{1}$

${ }^{1}$ Nova Southeastern University, Davie, Florida/United States of America

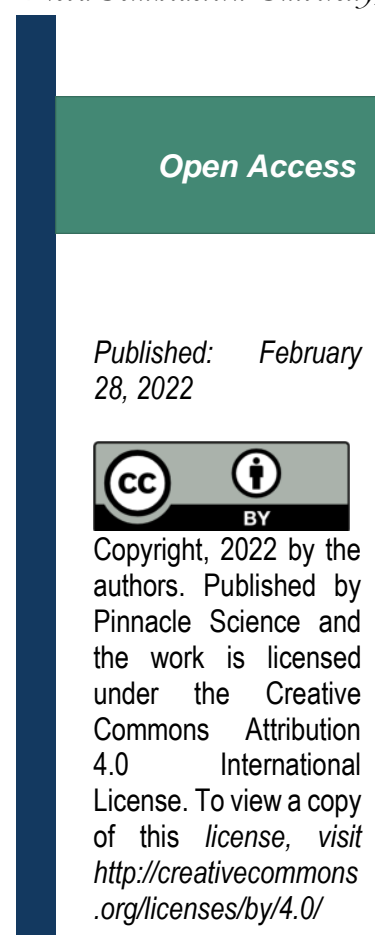

Research Directs in Strength and Performance: 2022,

ISSN: 2768-5187 Volume 2 (Issue 1): 3

\begin{abstract}
Introduction: Nutrition plays an important role for mixed martial art (MMA) athletes preparing for competition. Additionally, nutritional supplements are widely used by athletes preparing for competition. Among the various nutritional supplements used by MMA athletes, $\beta$-hydroxy- $\beta$-methylbutyrate (HMB) is one supplement that may have positive effects on body composition during a fight camp.

Methods: The current study examined 16 healthy, male professional MMA fighters (29.0 \pm 3.5 yrs.; $178.5 \pm 7.8 \mathrm{~cm}$ ). Participants completed a randomized, double-blinded, two group [HMB versus Placebo (Cellulose)] by two-time point [Pre-, Post-], mixed study. The study consisted of subjects supplementing HMB ( $3 g$ daily) or placebo in conjunction with MMA training over a 6-week period. Supplementation was consumed after each morning training session and first thing in the morning on nontraining days. Body composition was assessed via InBody770® (InBody UK, United Kingdom) for both pre- and post-intervention.

Results: There were no significant $(\mathrm{p}=0.471)$ differences between HMB and Placebo (Table 2) following the 6-weeks of training for weight (HMB Pre- $84.6 \pm 10.8 \mathrm{~kg}$, Post84.1 $\pm 11.6 \mathrm{~kg}$; Placebo Pre- $87.9 \pm 14.2 \mathrm{~kg}$, Post- $87.9 \pm 13.5 \mathrm{~kg}$ ). There were also no significant $(\mathrm{p}=0.095)$ differences for skeletal muscle mass (SMM) (HMB Pre$42.3 \pm 5.4 \mathrm{~kg}$, Post- $41.8 \pm 5.1 \mathrm{~kg}$; Placebo Pre- $44.2 \pm 9.0 \mathrm{~kg}$, Post- $44.6 \pm 8.8 \mathrm{~kg}$ ). No significant $(\mathrm{p}=0.655)$ differences existed for fat mass (HMB Pre- $11.3 \pm 2.5 \mathrm{~kg}$, Post-

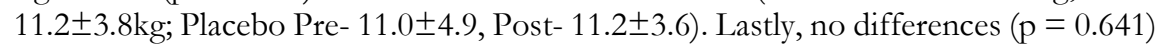
existed for body fat \% (HMB Pre- $13.3 \pm 2.5 \%$, Post- 13.2 $\pm 3.4 \%$; Placebo Pre$12.8 \pm 6.4 \%$, Post- $12.3 \pm 6.6 \%$ ).

Conclusion: Based on the results, the use of HMB to improve body composition in trained MMA fighters is not supported. There was also no significant difference in skeletal muscle mass during the six weeks.
\end{abstract}

Key Words: Sports Nutrition, Weight, Fat Percentage

Corresponding author: Jose Rojas, jr2564@mynsu.nova.edu

\section{Introduction}

Mixed Martial Arts (MMA) is growing in popularity due to both entertainment and competition it offers via hand to hand combat. While MMA is much more organized than its predecessor, the athletes still enter competition wearing minimal protective equipment while attacking their opponent with various strikes such as elbows, punches, knees and kicks ${ }^{1,2}$. The sport is not limited to strikes as it also includes submissions via chokes and joint manipulation as well as various throws and take downs. Fighters seek to secure victory via points scored on 
successful strikes, submissions, and leaving their opponent unconscious via knock outs, technical knock outs, or chokes $^{2}$.

As with most sporting activities, there are specific preparation methods used leading up to competition ${ }^{3}$. These methods include proper fight camps comprised of specific skill training as well as strength and conditioning programs. To support these intensive training programs, most fighters will also apply nutritional practices and rapid weight loss (RWL) methods to compete in specific weight divisions set by fight promotions or organizations. This is commonly referred to by fighters as weight cuts ${ }^{3}$. If a fighter practiced RWL methods to cut down from $175 \mathrm{lbs}$ to fight in the 145lbs division and gained back the weight prior to fighting, there would be a benefit from the size advantage over the opponent ${ }^{4}$. This is of course if proper RWL and rehydration methods are applied while minimizing any negative effects from RWL ${ }^{5}$. The purpose of MMA fight camps is to improve/prepare the athletes' skills, strength, reaction time, and power ${ }^{6}$. For this reason, MMA athletes seek to find the safest and most efficient methods to optimize their fight camp preparation and nutrition ${ }^{7}$.

As stated, nutrition plays an important role for MMA athletes preparing for competition. Among these nutritional practices, sports supplements play a vital role in the preparation for competition. Sport supplements can have various ergogenic effects that can enhance athletic performance and aid with improving body composition. Among the various sports supplements used by MMA athletes, $\beta$-hydroxy- $\beta$-methylbutyrate (HMB) is one such supplement that can have positive body composition effects during a fight camp $8,9,10,11$. HMB is a metabolite of the amino acid leucine, and in combination with resistance training, may increase lean muscle mass and decrease body fat ${ }^{8,10}$. Additionally, HMB has been known to inhibit protease activity ${ }^{10}$. Further research suggests that HMB will decrease muscle proteolysis after resistance training while augmenting gains in lean muscle mass, a desired effect for weight division sensitive MMA athletes $^{8}$. HMB has also been shown to stimulate muscle protein synthesis in skeletal muscle, thought to happen through the stimulation of the mTOR pathway and can help blunt the increase of skeletal muscle damage ${ }^{10,12,13}$. The goals of HMB supplementation during fight camp is to increase lean muscles mass, decrease body fat, and preserve the lean muscle mass gained.

Although RWL can negatively affect body composition and performance, there continues to be a high prevalence in RWL methods, particular to MMA3,7,14,15. With weight cuts via RWL prevalence reported as high as $90 \%$ across the board in combat sports, it is crucial that athletes and coaches apply the best practices during fight camp to minimize any deleterious effects ${ }^{15}$. In this context, the purpose of RWL methods is to come in heavier than the opponent and presumably have the strength and size advantage. Prior to the application of RWL methods, athletes strive to lower total body weight by reducing body fat via macronutrient restrictions and a hypocaloric diet ${ }^{7,16}$. Restricted dietary practices are typically coupled with a decrease in lean muscle mass ${ }^{6}$. With the known anti-proteolytic effects of HMB, the amount of lean muscle mass and strength lost during these dietary restrictions may be reduced ${ }^{17,18}$. The antiproteolytic effect would benefit the MMA athlete to keep any lean muscle mass gained during fight camp ${ }^{16}$. There is limited research on HMB supplementation habits for MMA athletes. Therefore, the purpose of this study was to investigate the effects of HMB supplementation on trained MMA athletes and body composition ${ }^{16,19}$. It was hypothesized that supplementing with HMB during a fight camp could be used to improve body composition and preserve lean body mass gained.

\section{Scientific Methods}

\section{Participants}

The current study examined 16 healthy, male professional MMA fighters $(29 \pm 3.5$ yrs.; $178.5 \pm 7.8 \mathrm{~cm})$. Participants completed a randomized, double-blinded, two group [HMB ( $\mathrm{n}=8)$ versus Placebo (Cellulose) $(\mathrm{n}=8)]$ by two-time point [Pre-, Post-], mixed design study. The study consisted of subjects supplementing HMB (3g daily) or placebo in conjunction with MMA training over a 6-week period (Table 1.)

\section{Protocol}

Supplementation was consumed after each AM training session and first thing in the morning on non-training days. Body composition was assessed via InBody770® (InBody UK, United Kingdom) for both pre- and post-intervention. For this assessment, subjects were asked to empty their bladder then remove their shoes, socks, and wipe down hands and feet with an InBody tissue to help with conductivity. The subjects then stepped on the electrode platform and waited for the automated software to measure weight. A subject number was assigned to the subject and height, age, and gender was entered. The subjects were instructed to align their heels with the electrodes and grab the handles keeping their arms straight and away from the body and placing their thumbs on the handle electrodes until the 
assessment was completed. The current study was approved by the University's Institutional Review Board and consent was obtained by all subjects.

Table 1. Example of training week for MMA Athletes

\begin{tabular}{|l|l|l|}
\hline Day & Training (AM) & Training (PM) \\
\hline Monday & MMA & Strength and Conditioning \\
\hline Tuesday & Sparring & Striking Techniques \\
\hline Wednesday & Wrestling & \\
\hline Thursday & Sparring & Strength and Conditioning \\
\hline Friday & BJJ & Grappling Techniques \\
\hline Saturday & Strength and Conditioning & \\
\hline Sunday & Recovery & \\
\hline
\end{tabular}

Legend: BJJ - Brazilian Jiu Jitsu; MMA - Mixed Martial Arts

\section{Statistical Analysis}

All data is presented as the mean \pm SD. SPSS (version 27) software was used for statistical analyses. A repeated measures ANOVA and post-hoc paired and independent t-test analysis was used to determine if statistically significant differences $(\mathrm{p}<0.05)$ exist between the HMB versus the placebo groups in MMA athletes.

\section{Results}

There were no significant $(\mathrm{p}=0.471$ ) differences between HMB and Placebo (Table 2) following the 6-weeks of

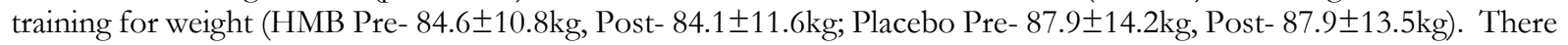
were also no significant $(\mathrm{p}=0.095)$ differences for skeletal muscle mass (SMM) (HMB Pre- 42.3 $\pm 5.4 \mathrm{~kg}$, Post-

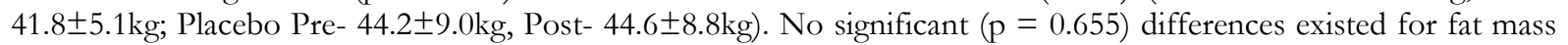

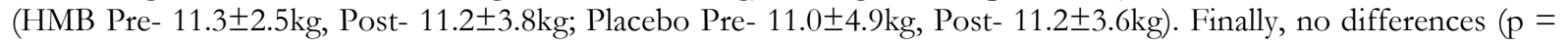
0.641 ) existed for body fat $\%$ (HMB Pre- $13.3 \pm 2.5 \%$, Post- $13.2 \pm 3.4 \%$; Placebo Pre- $12.8 \pm 6.4 \%$, Post- $12.3 \pm 6.6 \%$ ) (Table 2.)

Table 2. Differences (Mean $\pm \mathrm{SD})$ pre and post ingestion of either $\operatorname{HMB}(\mathrm{N}=8)$. or Placebo $(\mathrm{N}=8)$.

\begin{tabular}{|l|c|c|c|c|}
\hline & \multicolumn{2}{|c|}{ HMB } & \multicolumn{2}{c|}{ Placebo } \\
\hline & Pre & Post & Pre & Post \\
\hline Weight (Kgs) & $84.6 \pm 10.8$ & $84.1 \pm 11.6$ & $87.9 \pm 14.2$ & $87.9 \pm 13.5$ \\
\hline SMM (Kgs) & $42.3 \pm 5.4$ & $41.8 \pm 5.1$ & $44.2 \pm 9.0$ & $44.6 \pm 8.8$ \\
\hline Fat Mass (Kgs) & $11.3 \pm 2.5$ & $11.2 \pm 3.8$ & $11.0 \pm 4.9$ & $11.2 \pm 3.6$ \\
\hline Body Fat \% & $13.3 \pm 2.5$ & $13.2 \pm 3.4$ & $12.8 \pm 6.4$ & $12.3 \pm 6.6$ \\
\hline
\end{tabular}

\section{Discussion}

Contrary to previous findings by Jówko et al. and Wilson et al., the current study demonstrated non-significant differences between HMB and Placebo in the sample of professional MMA fighters ${ }^{10,20}$. This may in part be due to the population's training schedule as opposed to the other populations used in the previous studies. This may also be due to the short intervention time of six weeks used. With the effect on muscle protein synthesis gained from HMB it was hypothesized that there would be an increase in lean body mass and a decrease in fat mass. While previous studies referenced a positive effect on body composition, there have been studies to show similar results to this current study. One study by Kreider et al. showed 3g/d of HMB supplementation for a 4-week period had no significant effect on body composition ${ }^{19}$. However, the study by Lowery et al. examined $3 \mathrm{~g} / \mathrm{d}$ of HMB supplementation during a 12-week period and found that HMB did significantly improve body composition and blunted the increase in muscle damage leading to an increase in lean body mass of $8.5 \pm 0.8 \mathrm{~kg}$ and a decrease in body fat percentage of $8.5 \pm 0.9 \%$; the placebo group resulted in $2.1 \pm 0.5 \mathrm{~kg}$ increase in lean body mass and a decrease of $2.4 \pm 1.1 \%$ in body fat percentage ${ }^{12}$. The result may be due to its length of intervention, perhaps a longer period of supplementation could have shown different results ${ }^{10,19}$.

A position stand from the International Society of Sports Nutrition suggests that HMB in conjunction with a structured exercise program may result in greater reductions in fat mass ${ }^{10}$. Additionally, there is an expected increase in lean muscle mass due to the inhibition of proteolysis and increase in muscle protein synthesis ${ }^{10,20}$. Again, the lack of 
significant results in the current study may be due to the demands of an MMA athlete rather than sedentary individuals or individuals who are solely relying on resistance training. There are several possible reasons for the discrepancy in results observed. It may be possible that HMB supplementation may be more effective in untrained subjects initiating training rather than currently trained individuals ${ }^{19}$. This study has its limitations, which include subject size, intervention length, and the between-subjects design. All these variables may have affected the overall results. Results in the current six-week intervention study did not support the use of HMB to improve body composition in trained MMA fighters. There was also no difference between groups in maintaining skeletal muscle mass during the 6 -weeks. This study only collected data from 16 subjects during a 6 -week period, and there were no significant differences between the groups. Future studies should examine different intervention lengths, larger sample sizes, and different phases or stages of fight camps.

\section{References}

1. Buse, G Burke, L. M., Slater, G. J., Matthews, J. J., Langan-Evans, C., \& Horswill, C. A.. J. (2006). No holds barred sport fighting: a 10 year review of mixed martial arts competition. British journal of sports medicine, 40(2), 169-172.

2. Poliakoff, M. B. (1987). Combat sports in the ancient world: Competition, violence, and culture. Yale University Press.

3. Barley, O. R., Chapman, D. W., \& Abbiss, C. R. (2018). Weight loss strategies in combat sports and concerning habits in mixed martial arts. International journal of sports physiology and performance, 13(7), 933-939.

4. Murugappan, K. R., Mueller, A., Walsh, D. P., Shaefi, S., Leibowitz, A., \& Sarge, T. (2021). Rapid Weight Gain Following Weight Cutting in Male and Female Professional Mixed Martial Artists. International journal of sport nutrition and exercise metabolism, 31(3), 259-267.

5. Khodaee, M., Olewinski, L., Shadgan, B., \& Kiningham, R. R. (2015). Rapid weight loss in sports with weight classes. Current sports medicine reports, 14(6), 435-441.

6. Franchini, E., Brito, C. J., \& Artioli, G. G. (2012). Weight loss in combat sports: physiological, psychological and performance effects. Journal of the International Society of Sports Nutrition, 9(1), 1-6.

7. Brito, C. J., Roas, A. F. C. M., Brito, I. S. S., Marins, J. C. B., Córdova, C., \& Franchini, E. (2012). Methods of body-mass reduction by combat sport athletes. International journal of sport nutrition and exercise metabolism, 22(2), 89-97.

8. Nissen, S., Sharp, R., Ray, M., Rathmacher, J., Rice, D., Fuller Jr, J., Connelly, A., \& Abumrad, N. (1996). Effect of leucine metabolite $\beta$-hydroxy- $\beta$-methylbutyrate on muscle metabolism during resistance-exercise training. Journal of Applied Physiology, 81(5), 2095-2104.

9. Tsuchiya, Y., Ueda, H., Sugita, N., \& Ochi, E. (2021). Low Dose of $\beta$-Hydroxy- $\beta$-Methylbutyrate (HMB) Alleviates Muscle Strength Loss and Limited Joint Flexibility following Eccentric Contractions. Journal of the American College of Nutrition, 40(3), 211-218.

10. Wilson, J. M., Fitschen, P. J., Campbell, B., Wilson, G. J., Zanchi, N., Taylor, L., Wilborn, C., Kalman, D. S., Stout, J. R., \& Hoffman, J. R. (2013). International society of sports nutrition position stand: beta-hydroxybeta-methylbutyrate (HMB). Journal of the International Society of Sports Nutrition, 10(1), 1-14.

11. (2021). ACSM Expert Consensus Statement on Weight Loss in Weight-Category Sports. Current sports medicine reports, 20(4), 199-217.

12. Lowery, R. P., Joy, J. M., Rathmacher, J. A., Baier, S. M., Fuller, J. C., Shelley, M. C., Jäger, R., Purpura, M., Wilson, S., \& Wilson, J. M. (2016). Interaction of beta-hydroxy-beta-methylbutyrate free acid and adenosine triphosphate on muscle mass, strength, and power in resistance trained individuals. Journal of strength and conditioning research, 30(7), 1843-1854.

13. Sikorski, E. M., Wilson, J. M., Lowery, R. P., Duncan, N., Davis, G., Rathmacher, J., Baier, S., Naimo, M., Wilson, S. M., \& Dunsmore, K. (2012). The acute effects of a free acid beta-hydoxy-beta-methyl butyrate supplement on muscle damage following resistance training: a randomized, double-blind, placebo-controlled study. Journal of the International Society of Sports Nutrition, 9(1), 1-2.

14. Matthews, J. J., Stanhope, E. N., Godwin, M. S., Holmes, M. E., \& Artioli, G. G. (2019). The magnitude of rapid weight loss and rapid weight gain in combat sport athletes preparing for competition: A systematic review. International journal of sport nutrition and exercise metabolism, 29(4), 441-452.

15. Hillier, M., Sutton, L., James, L., Mojtahedi, D., Keay, N., \& Hind, K. (2019). High prevalence and magnitude of rapid weight loss in mixed martial arts athletes. International journal of sport nutrition and exercise metabolism, 29(5), 512-517.

16. Langan-Evans, C., Close, G. L., \& Morton, J. P. (2011). Making weight in combat sports. Strength \& Conditioning Journal, 33(6), 25-39. 
17. Pallarés, J., Martínez-Abellán, A., López-Gullón, J., Morán-Navarro, R., De la Cruz-Sánchez, E., \& MoraRodríguez, R. (2016). Muscle contraction velocity, strength and power output changes following different degrees of hypohydration in competitive olympic combat sports. Journal of the International Society of Sports Nutrition, 13(1), 1-9.

18. Roklicer, R., Lakicevic, N., Stajer, V., Trivic, T., Bianco, A., Mani, D., Milosevic, Z., Maksimovic, N., Paoli, A., \& Drid, P. (2020). The effects of rapid weight loss on skeletal muscle in judo athletes. Journal of translational medicine, 18(1), 1-7.

19. Kreider, R. B., Ferreira, M. P., Greenwood, M., Wilson, M., Grindstaff, P., Plisk, S., Reinardy, J., Cantler, E., \& Amalda, A. L. (2000). Effects of calcium $\beta$-HMB supplementation during training on markers of catabolism, body composition, strength and sprint performance.

20. Jówko, E., Ostaszewski, P., Jank, M., Sacharuk, J., Zieniewicz, A., Wilczak, J., \& Nissen, S. (2001). Creatine and $\beta$-hydroxy- $\beta$-methylbutyrate $(\mathrm{HMB})$ additively increase lean body mass and muscle strength during a weight-training program. Nutrition, 17(7-8), 558-566. 